\title{
Consuming More than Just Stories: Does What Children Watch on TV While Eating Influence how Much they Eat?
}

\author{
Gregory P. Traversy ${ }^{1,2}$, Michael M. Borghese ${ }^{1,2}$, Zachary M. Ferraro ${ }^{1,3}$ and Jean-Philippe Chaput ${ }^{1,4, *}$ \\ ${ }^{I}$ Healthy Active Living and Obesity Research Group, Children's Hospital of Eastern Ontario Research Institute, Ottawa, \\ Ontario, Canada \\ ${ }^{2}$ School of Human Kinetics, Faculty of Health Sciences, University of Ottawa, Ottawa, Ontario, Canada \\ ${ }^{3}$ Division of Maternal-Fetal Medicine, The Ottawa Hospital-General Campus, Ottawa, Ontario, Canada \\ ${ }^{4}$ Department of Pediatrics, Faculty of Medicine, University of Ottawa, Ottawa, Ontario, Canada
}

\begin{abstract}
Television (TV) viewing is a risk factor for obesity in children. This is partly due to its promotion of energy intake by distracting from normal satiety signals. Children are exposed to a variety of TV programs which differ in features such as pacing. This is reason to believe that different children's TV shows distract to varying degrees, and can therefore influence energy intake to different extents. We suggest that future research should examine how different TV shows influence energy intake in children. Such research could help identify new ways to protect children from the negative effects of TV viewing on caloric intake and ultimately body weight.
\end{abstract}

Keywords: Children, food intake, obesity, satiety, sedentary behavior, television

\section{INTRODUCTION}

The prevalence of obesity has increased dramatically in children and adolescents over the past 30 years. In North America, approximately $29 \%$ of children are currently overweight or obese [1]. Sedentary behaviors are increasingly targeted as potential facilitators of weight gain. Television (TV) viewing is among the sedentary behaviors believed to promote a positive energy balance in children [2].

TV viewing is universal in the lives of children. In 2013, American children aged 2-11 and aged 12-17 watched roughly 113 hours and 98.5 hours of TV per month, respectively [3]. These data did not include pre-recorded TV shows, or those watched on DVD, suggesting that the exposure to TV content is likely greater than reported [3]. Given these statistics it is not surprising that children can consume up to $25 \%$ of their total caloric intake in front of the TV [4].

TV viewing has been linked with obesity in children, and several hypotheses have been proposed to explain this association [5-9]. Eating while watching TV, for instance, has been shown to increase energy intake [5, 10-13]. The objective of this article is to provide direction for future research in the area of TV viewing and obesity in children

\footnotetext{
*Address correspondence to this author at the Healthy Active Living and Obesity Research Group, Children's Hospital of Eastern Ontario Research Institute, 401 Smyth Road, Ottawa, Ontario, Canada, K1H 8L1;

Tel: +1 613737 7600; ext. 3683; Fax: +1 613738 4800;

E-mail: jpchaput@cheo.on.ca
}

based on the current literature. To the authors' knowledge, currently there does not appear to be any published research regarding whether different varieties of TV shows have different influences on energy intake in children. Based on the available evidence, it is likely that children's TV programs may differentially impact energy intake because of how they distract viewers, potentially delaying the onset and reducing the impact of satiety signals [5, 10-13]. Future research should investigate this potential phenomenon and evaluate how it affects child consumption as this may provide important insight for parents wishing to lessen the impact of TV viewing on their children's health. These results may help inform strategies aimed at improving energy intake and ultimately public health.

\section{TELEVISION, ENERGY BALANCE, AND OBESITY}

The association between TV viewing and obesity is well documented with several longitudinal, cross-sectional, and intervention studies identifying TV time as a predictor of overweight and obesity in both adults and children [14-23]. In children, this link has been demonstrated across a variety of age ranges, in both genders, and in multiple ethnicities [4$6,14-16,18-24]$. A recent cross-sectional study also found that excessive TV time ( $>2$ hours/day) was positively and significantly associated with waist circumference in 5-6 year-olds, although this relationship was not significant in individuals watching less than two hours of TV per day [25]. It has thus been suggested that decreasing TV viewing may be one of the most successful ways to reduce the impact of childhood obesity [26]. 
TV viewing has been proposed to promote obesity by displacing physical activity time, and decreasing energy expenditure $[8,9]$. However, contradictory results have cast doubt on these hypotheses [22, 27-32]. TV viewing may influence energy balance and weight by disrupting circadian rhythm and cortisol secretion [33, 34]. Also, advertisements during children's programming may influence food decisions, and dietary habits by promoting obesogenic foods $[14,19,35-38]$. Finally, TV has been shown to increase energy intake by distracting viewers from satiety [5, 7-13]. Indeed, in a randomized controlled trial, children whose screen time was reduced showed decreases in BMI that were attributed in part to decreased energy intake [23]. Similarly, a recent cross-sectional study identified watching TV while eating dinner as a correlate of adult and child BMI [39]. Another recent cross-sectional analysis found that children who reported never watching TV while eating lunch or dinner had lower risk of overweight than those who did watch TV during meals [20]. This is echoed by the fact that a recent randomized controlled trial targeting TV time that failed to elicit a significant change in screen time between intervention and control groups also failed to decrease BMI and other adiposity measures in children [40].

Advertisements must be only partially to blame, however, as increased energy intake during TV watching is demonstrated in experimental conditions where commercials are excluded $[5,11]$. The increase in energy intake in these cases is most likely due to the distracting nature of TV programs. This is supported by the fact that TV watching increases food intake regardless of hunger and satiety, suggesting that viewers are distracted from internal satiety signaling $[5,10]$. The disruption of normal satiety signaling has been proposed as the reason that eating while watching TV leads to increased meal frequency and shorter meal-tomeal intervals [13]. Furthermore, other distracting situations, such as listening to music or a recorded story, eating along with friends, or playing a computer game all also increase energy intake in the absence of hunger [10, 12, 13, 41]. It is this distracting nature of TV programs that is the focus of this article and, as proposed by the authors, should be further examined in future studies.

\section{VARIETY IN CHILDREN'S PROGRAMMING}

Individuals familiar with children's TV programming will be cognizant of the fact that children are exposed to a wide variety of programming. A national study of children's TV shows in Canada found that the programs aimed towards children fell into a variety of categories, including informal and formal education, drama, comedy, and action adventure [42]. The categories of programs differed depending on the broadcasting company, the language of broadcast, the country of origin of the program, and the target audience [42]. Many of the shows analyzed in this report originated from the USA and other foreign sources, exemplifying the diversity of programming [42]. Further, another analysis, of 443.5 hours of children's programming in America found that the content of TV shows varied by network as well as by individual show [43].
Furthermore, children's TV shows differ with respect to features such as the frequency of edits or cuts, the presence of music, the amount of movement and rapid action, the presence of dialogue, and the presence of singing, among others [44-46]. Huston et al. [45] identified and compared the features of 137 children's programs, finding that some of these features varied depending on whether the show was humorous vs. serious, animated vs. live, or educational vs. commercial. Hooper and Chang [44] found that the number of events requiring attentional shifts of the viewer varied among 13 different children's shows. For instance, 20 minutes of Sesame Street contained 152 events requiring a shift in visual attention of the observer, while Winnie the Pooh contained 399 such events [44]. More recently, McCollum and Bryant [46] found that the pacing varied widely among 85 children's TV programs, with commercial networks generally having more fast-paced shows. They also found that curriculum-based TV programs (e.g. child education programs) had lower pacing on average than other types of shows, as defined by the number of cuts and edits (50\% of pacing score), music and dialogue (30\%), and onscreen movement (20\%) [46]. These studies share some common limitations. The quantification and coding of formal features is not standardized and is determined by the researchers, leaving it open to some subjectivity [44-46]. Further, older studies may not accurately represent today's television broadcasting, as the body of children's programming is large and ever changing. Finally, these studies do not specifically examine how these features influence how distracting the shows are to children. However, the body of evidence, when taken together, is effective in demonstrating that the programming children are exposed to throughout the day is not homogenous. Thus, it stands to reason that they are not always exposed to the same types of TV shows while eating.

\section{DOES WHAT CHILDREN WATCH WHILE THEY EAT INFLUENCE HOW MUCH THEY EAT?}

The body of research examining the effect of TV viewing on energy intake has consistently shown that TV viewing increases food intake. However, the effects have been varied, with some studies reporting only modest increases in energy intake, and others showing rather large increases in energy intake [5, 11, 47]. Blass et al. found that undergraduate students ate $36 \%$ more calories from pizza while watching $\mathrm{TV}$, but $71 \%$ more calories when macaroni and cheese was the food given, suggesting an effect of the type of food being eaten [47]. Indeed, it is proposed that TV viewing has a strong effect on the intake of calorically dense foods [10, 47]. However, Belissimo et al. [5] also examined pizza consumption, this time in young boys, and found a smaller increase in energy intake. This is undoubtedly due in part to the personal characteristics of the study participants. For instance, Martin et al. [48] noted that an individual's distractibility accounted for $13 \%$ of the variance in energy intake for their male participants. Further, factors such as age, gender, ethnicity and socio-economic status have varied among studies and likely also contribute to varying results, despite the trend towards increased intake with TV viewing 
$[5,11,20,23,40,47]$. In addition to potential confounders at the level of the individual, the discrepant results between studies are likely also due to the fact that studies that have examined the effect of TV viewing on energy intake in children and adults have used a wide variety of TV shows in their protocols (i.e., the exposure has not been standardized). Some studies have allowed the participants to watch TV shows of their choice [47, 49]; others have used clips from children's cartoons [11], The Simpsons [5], or pre-recorded tapes [10]; finally, some studies have not indicated which TV shows were watched due to the nature of the data collection methods [13].

Likewise, the TV programs that children watch in their day-to-day lives are not delivered in standardized doses, due to the heterogeneous nature of the programming. If $\mathrm{TV}$ promotes energy intake by distracting individuals from normal satiety signaling, and not all children's shows are equally distracting, then the content and features of TV programs can influence the amount and composition of foods eaten. This hypothesis is supported with empirical data. First, the formal features of TV shows alter the attentional demand of the show. Lang et al. [50] showed that TV shows with more cuts and edits increased arousal and attention to TV shows in college-aged subjects. In addition, four-yearold children who watched fast paced TV shows showed signs of cognitive depletion, leading to impaired selfregulation, although this was not evaluated in other age ranges [51]. A TV show with a high number of camera edits such as Dragonball Z, which was found to have 99 edits in a 5 minute segment, is therefore likely to require more attention, and be more distracting, than a show like Bill Nye the Science Guy, which had only 16 edits in 5 minutes [46].

It has also been suggested that children pay more attention to the dialogue of children in TV shows, and pay less attention to the dialogue of adults [52]. Child dialogue was found to be slightly more common in serious shows compared to humorous shows in the analysis carried out by Huston et al. [45]. Commercial TV programs were slightly more likely to be associated with adult dialogue than educational programs in the same analysis [45].

Finally, the ability to comprehend a TV program has also been shown to increase attentional focus of 5-year-olds watching a TV program, as measured by their performance in a probe task [53]. Indeed, attention to TV has been shown to increase during preschool years and peak during the school-aged years supposedly due to increased comprehension [52].

Thus, there is sufficient evidence to suggest that children's TV shows likely differ in their ability to distract the attention of young watchers. Consequently, it is possible that different TV shows can increase energy intake to differing degrees. A study that touched upon this potential effect was done by Lyons, Tate and Ward [49]. They found a significant association between the 'narrative transport' of a TV show and caloric intake in 120 adults, but not between the other measures of distraction and intake [49]. Narrative transportation is described as a measure of how involved one becomes in the story being presented [54]. It includes 'emotional involvement in the story, cognitive attention to the story, feelings of suspense, lack of awareness of surroundings, and mental imagery'[54]. However, very few, if any, studies have directly evaluated the effect of different TV shows on energy intake in children. Temple et al. [55] had children watching one of three different shows and noted that while TV viewing increased energy intake in all cases, there were no significant differences between groups. This however does not account for individual variability, as each participant watched only one of the three shows [55]. A recent experiment by Tal et al. [56] provides direct evidence that different TV shows influence food intake differently. Participants watched an action movie, an interview-based TV show, or the action movie without sound, and found that caloric intake was increased by $65 \%$ while watching the action movie, compared to the interview-based show [56]. The action movie differed largely from the interview-based show in its distracting features such as the number of camera cuts, and sound variation thus lending support to our hypothesis [56]. When the action movie was viewed without sound, thus eliminating one source of distraction, fewer calories were eaten, although the intake was still higher than while watching the interview show [56]. This study, however, was done in university undergraduates and thus it remains to be seen whether or not these results would translate to children [56].

\section{DISCUSSION}

The current body of evidence suggests that different TV shows may differentially influence energy intake, as the level of distraction offered by different TV shows can vary. The question is therefore whether this can result in truly significant differences in caloric intake while watching different shows. Is more distraction associated with an increased lack of perception of satiety signals, and therefore increased energy intake? Or could it be that our ability to monitor signals of satiety is sufficiently sensitive that any TV show is distracting enough to cause individuals to ignore them? The results obtained by Tal et al. [56] lend support to the former theory. Participants watching a more distracting program (based on camera edits and sound fluctuation) consumed more calories [56].

Future studies should evaluate how different children's programs (e.g. Dragon Ball Z compared to Scooby Doo) influence immediate ad libitum food intake, as well as intake in the days following exposure to the TV show. This research is particularly important in the context of children due to the pervasiveness of $\mathrm{TV}$ in their lives, and the frequency with which children eat in front of the TV $[3,4]$.

\section{IMPLICATIONS AND CONCLUDING REMARKS}

If different TV shows influence energy intake in children differently, then it may represent another way for parents to monitor and take control over how TV influences their children's lives. Recent longitudinal and prospective cohort studies suggest that parental monitoring of children's screen time comes with a multitude of benefits for children, 
including lower BMI [57, 58]. Measures of parental monitoring include setting limits on content and amount of screen time, as well as having active discussion about content [57]. If different TV shows demonstrate sufficient differences in terms of their impact on energy intake, then controlling during which shows children are allowed to eat meals or snacks may represent another way that parents can monitor their children's screen time. Furthermore, such a recommendation may be more easily implemented than attempting to prevent children from watching TV, or eating in front of the TV, all together. Although the American Academy of Pediatrics' (APP) policy statement on Children, Adolescents, and the Media suggests that parents limit children's screen time to less than 1-2 hours per day, children aged 2-11 continue to watch approximately 3.6 hours of TV per day $[3,59]$. Similarly, the AAP suggests that parents enforce screen-free mealtimes, yet it is estimated that children can consume up to $25 \%$ of their daily caloric intake in front of the TV $[4,59]$.

Understanding the variation in child consumption while viewing a diverse range of programs will also broaden the scope of knowledge surrounding the impact of TV watching and other screen-time activities on energy intake. The results of these studies may lend support to the theory that the increased energy intake seen with TV watching is due to the distraction caused by the TV program. It may also help researchers determine more specifically which aspects of TV programs influence distraction and energy intake in children. Conversely, if different TV shows do not have differential effects on energy intake this result also warrants discussion. First, it would hint at the sensitivity of satiety perception mechanisms to distractions. If all TV shows are sufficiently distracting to prevent proper perception of satiety, despite varying in their distracting features, it suggests that there is a finite amount of distraction that can be tolerated before we lose the ability to properly attend to signals of satiety. Alternatively, it may suggest that there are other factors that influence energy intake that are being influenced by TV. Perhaps individuals are being distracted from their satiety signals to different extents, but this effect is being concealed by some other influence, such as excitement or agitation. Furthermore, this information could demonstrate to parents the power of TV shows to influence their children's energy intake, regardless of the show's formal features. This could act as a motivating factor for parents adhere more strictly to the AAP's recommendation to restrict TV watching during mealtime.

The effect that different TV shows have on energy intake in children represents a gap in current knowledge. Attending to this void in the literature is likely to provide interesting and important information pertaining to child and public health. Given the pervasiveness of TV in the lives of children and youth, and their propensity for eating in front of the $\mathrm{TV}$, it is of utmost importance for parents and practitioners to be fully aware of how TV influences energy intake. As we discover more about the relationship between TV and energy intake we will inevitably become more adept at moderating the effects of screen time on overweight and obesity.

\section{CONFLICT OF INTEREST}

The authors confirm that this article content has no conflict of interest.

\section{ACKNOWLEDGEMENTS}

Greg Traversy is supported by a summer studentship from the Children's Hospital of Eastern Ontario Research Institute. Michael Borghese is supported by an Ontario Graduate Scholarship from the University of Ottawa. Zach Ferraro holds a Canadian Institutes of Health Research (CIHR) Postdoctoral Fellowship. Jean-Philippe Chaput holds a Junior Research Chair in Healthy Active Living and Obesity Research.

\section{REFERENCES}

[1] $\mathrm{Ng} \mathrm{M}$, Fleming $\mathrm{T}$, Robinson $\mathrm{M}$, et al. Global, regional, and national prevalence of overweight and obesity in children and adults during 1980-2013: a systematic analysis for the global burden of disease study 2013. Lancet 2014; 384: 766-81.

[2] Chaput J, Klingenberg L, Astrup A, Sjodin AM. Modern sedentary activities promote overconsumption of food in our current obesogenic environment. Obes Rev 2011; 12: e12-20.

[3] Nielsen. Free to move between screens: The cross-platform report. 2013: pp. 1-22.

[4] Matheson DM, Killen JD, Wang Y, Varady A, Robinson TN. Children's food consumption during television viewing. Am J Clin Nutr 2004; 79: 1088-94.

[5] Bellissimo N, Pencharz PB, Thomas SG, Anderson GH. Effect of television viewing at mealtime on food intake after a glucose preload in boys. Pediatr Res 2007; 61: 745-9.

[6] Dietz WH, Gortmaker SL. Do we fatten our children at the television set? Obesity and television viewing in children and adolescents. Pediatrics 1985; 75: 807-12.

[7] Jenvey V. The relationship between television viewing and obesity in young children: a review of existing explanations. Early Child Dev Care 2007; 177: 809-20.

[8] Klesges RC, Shelton ML, Klesges LM. Effects of television on metabolic rate: potential implications for childhood obesity. Pediatrics 1993; 91: 281-6.

[9] Mutz DC, Roberts DF, van Vuuren DP. Reconsidering the displacement hypothesis: television's influence on children's time use. Communic Res 1993; 20: 51-75.

[10] Bellisle F, Dalix AM, Slama G. Non food-related environmental stimuli induce increased meal intake in healthy women: comparison of television viewing versus listening to a recorded story in laboratory settings. Appetite 2004; 43: 175-80.

[11] Francis LA, Birch LL. Does eating during television viewing affect preschool children's intake? J Am Diet Assoc 2006; 106: 598-600.

[12] Hetherington MM, Anderson AS, Norton GNM, Newson L. Situational effects on meal intake: a comparison of eating alone and eating with others. Physiol Behav 2006; 88: 498-505.

[13] Stroebele N, de Castro JM. Television viewing is associated with an increase in meal frequency in humans. Appetite 2004; 42: 111-3.

[14] Caroli M, Argentieri L, Cardone M, Masi A. Role of television in childhood obesity prevention. Int J Obes Relat Metab Disord 2004; 28 (Suppl 3): S104-8.

[15] Ekelund U, Brage S, Froberg K, et al. TV viewing and physical activity are independently associated with metabolic risk in children: the European youth heart study. PLoS Med 2010; 3: e488.

[16] Gortmaker SL, Must A, Sobol AM, Peterson K, Colditz GA, Dietz WH. Television viewing as a cause of increasing obesity among children in the united states. JAMA Pediatr 1996; 150: 356-62.

[17] Hu FB, Li TY, Colditz GA, Willett WC, Manson JE. Television watching and other sedentary behaviours in relation to risk of obesity and type 2 diabetes mellitus in women. JAMA 2003; 289: 1785-91. 
[18] Liang T, Kuhle S, Veugelers PJ. Nutrition and body weights of canadian children watching television and eating while watching television. Public Health Nutr 2009; 12: 2457-63.

[19] Lobstein T, Dibb S. Evidence of a possible link between obesogenic food advertising and child overweight. Obes Rev 2005; 6: 203-8.

[20] Vik FN, Bjornara HB, Overby NC, et al. Associations between eating meals, watching TV while eating meals and weight status among children, ages 10-12 years in eight European countries: the ENERGY cross-sectional study. Int J Behav Nutr Phys Act 2013; 10: $1-10$.

[21] Must A, Tybor DJ. Physical activity and sedentary behaviour: a review of longitudinal studies of weight and adiposity in youth. Int J Obes 2005; 29: S84-6.

[22] Proctor MH, Moore LL, Gao D, et al. Television viewing and change in body fat from preschool to early adolescence: the framingham children's study. Int J Obes 2003; 27: 827-33.

[23] Epstein LH, Roemmich JN, Robinson JL, et al. A randomized trial of the effects of reducing television use on body mass index in young children. JAMA Pediatr 2008; 162: 239-45.

[24] Robinson TN. Television viewing and childhood obesity. Pediatr Clin North Am 2001; 48: 1017-25.

[25] Chinapaw M, Altenburg T, Eijsden M, Gemke R, Vrijkotte T. Screen time and cardiometabolic function in dutch 5-6 year olds: cross-sectional analysis of the ABCD-study. BMC Public Health 2014; 14: 933

[26] Dennison BA, Edmunds LS. The role of television in childhood obesity. Prog Pediatr Cardiol 2008; 25: 191-7.

[27] Andersen RE, Crespo CJ, Bartlett SJ, Cheskin LJ, Pratt M. Relationship of physical activity and television watching with body weight and level of fatness among children: results from the third national health and nutrition examination survey. JAMA 1998; 279: 938-42.

[28] de Jong E, Visscher T, HiraSing R, Heymans M, Seidell C, Renders C. Association between TV viewing, computer use and overweight, determinants and competing activities of screen time in 4- to 13-year-old children. Int J Obes 2013; 37: 53.

[29] Katzmarzyk P, Malina R, Song T, Bouchard C. Television viewing, physical activity, and health-related fitness of youth in the Québec family study. J Adolesc Health 1998; 23: 318-25.

[30] Dietz W, Bandini L, Morelli J, Peers K, Ching P. Effect of sedentary activities on resting metabolic rate. Am J Clin Nutr 1994; 59: 556-9.

[31] Lanningham-Foster L, Jensen T, Foster R, et al. Energy expenditure of sedentary screen time compared with active screen time for children. Pediatrics 2006; 118: 1831-5.

[32] Sun R, Piao JH, Tian Y, et al. Energy expenditure in reading and watching TV studied on 30 young females. Zhonghua Yu Fang Yi Xue Za Zhi 2008; 42: 196-8.

[33] Garaulet M, Odovás JM, Madrid JA. The chronobiology, etiology and pathophysiology of obesity. Int J Obes 2010; 34: 1667-83.

[34] Stunkard MD, Lu X. Rapid changes in night eating: considering mechanisms. Eat Weight Disord 2010; 15: e2-8.

[35] Batada A, Seitz MD, Wootan MG, Story M. Nine out of 10 food advertisements shown during saturday morning children's television programming are for foods high in fat, sodium, or added sugars, or low in nutrients. J Am Diet Assoc 2008; 108: 673-8.

[36] Borzekowski DL, Robinson TN. The 30-second effect: An experiment revealing the impact of television commercials on food preferences of preschoolers. J Am Diet Assoc 2001; 101: 42-6.

[37] Dixon HG, Scully ML, Wakefield MA, White VM, Crawford DA. The effect of television advertisements for junk food versus nutritious food on children's food attitudes and preferences. Soc Sci Med 2007; 65: 1311-23.
[38] Harrison K, Marske A. Nutritional content of foods advertised during the television programs children watch most. Am J Public Health 2005; 95: 1568-74.

[39] Wansink B, van Kleef E. Dinner rituals that correlate with child and adult BMI. Obesity 2014; 22: E91-5.

[40] Maddison R, Marsh S, Foley L, et al. Screen-time weight-loss intervention targeting children at home $(\mathrm{SWITCH})$ : a randomized controlled trial. Int J Behav Nutr Phys Act 2014; 11: 111.

[41] Brunstrom JM, Mitchell GL. Effects of distraction on the development of satiety. Br J Nutr 2006; 96: 761-9.

[42] Caron AH, Caronia LM, Hwang JM, et al. A national study on children's television programming in Canada. 2010: pp. 1-36.

[43] Parents Television Council. Wolves in sheep's clothing: a content analysis of children's television. 2006: 1-18

[44] Hooper M, Chang P. Comparison of demands of sustained attentional events between public and private childen's telvision programs. Percept Mot Skills 1998; 86: 431-4.

[45] Huston AC, Wright JC, Wartella E, et al. Communicating more than content: formal features of children's television programs. J Commun 1981; 31: 32-48.

[46] McCollum JF, Bryant J. Pacing in children's television programing. Mass Comm Soc 2003; 6: 115-36.

[47] Blass EM, Anderson DR, Kirkorian HL, Pempek TA, Price I, Koleini MF. On the road to obesity: television viewing increases intake of high-density foods. Physiol Behav 2006; 88: 597-604.

[48] Martin CK, Coulon SM, Markward N, Greenway FL, Anton SD. Association between energy intake and viewing television, distractibility, and memory for advertisements. Am J Clin Nutr 2009; 89: 37-44.

[49] Lyons EJ, Tate DF, Ward DS. The better the story, the bigger the serving: narrative transportation increases snacking during screen time in a randomized trial. Int J Behav Nutr Phys Act 2013; 10: 16.

[50] Lang A, Zhou S, Schwartz N, Bolls PD, Potter RF. The effects of edits on arousal, attention, and memory for television messages: when an edit is an edit can an edit be too much. J Broadcast Electron 2000; 44: 94-109.

[51] Lillard AS, Peterson J. The immediate impact of different types of television on young children's executive function. Pediatrics 2011; 128: e1-6.

[52] Anderson DR, Lorch EP, Field DE, Collins PA, Nathan JG, Television viewing at home: age trends in visual attention and time with TV. Child Dev 1986; 57: 1024-33.

[53] Lorch EP, Castle VJ. Preschool children's attention to television: visual attention and probe response times. J Exp Child Psychol 1997; 66: 111-27.

[54] Green MC, Brock TC. The role of transportation in the persuasiveness of public narratives. J Pers Soc Psychol 2000; 79: 701-21.

[55] Temple JL, Giacomelli AM, Kent KM, Roemmich JN, Epstein LH. Television watching increases motivated responding for food and energy intake in children. Am J Clin Nutr 2007; 85: 355-61.

[56] Tal A, Zuckerman S, Wansink B. Watch what you eat: actionrelated television content increases food intake. JAMA Intern Med (in press).

[57] Gentile DA, Reimer RA, Nathanson AI, Walsh DA, Eisenmann JC. Protective effects of parental monitoring of children's media use. JAMA Pediatr 2014; 168: 479-84.

[58] Tiberio SS, Kerr DC, Capaldi DM, Pears KC, Kim HK, Nowicka P. Parental monitoring of children's media consumption: the longterm influences on body mass index in children. JAMA Pediatr 2014; 168: 414-21.

[59] American Academy of Pediatrics. Policy statement: children, adolescents, and the media. Pediatrics 2013; 132: 958-61.

\footnotetext{
Received: August 18, 2014

Revised: October 13, 2014

Accepted: October 15, 2014

(C) Traversy et al.; Licensee Bentham Open.

This is an open access article licensed under the terms of the Creative Commons Attribution Non-Commercial License (http://creativecommons.org/licenses/by-nc/3.0/) which permits unrestricted, non-commercial use, distribution and reproduction in any medium, provided the work is properly cited.
} 